\title{
Simultaneous Determination Of U(Vi) and Pd (Ii) Using 4-Hydroxybenzaldehyde Thiosemicarbazone By Second Order Derivative Spectrophotometric Technique
}

\author{
Satheesh KP ${ }^{1}$, Pradeep Raju B ${ }^{1}$, Suresh Kumar ${ }^{2 *}$ and Padma Suvarna $\mathbf{R}^{2}$ \\ ${ }^{1}$ Department of chemistry, JNTUA, Anantapuramu (A.P), India \\ ${ }^{2}$ Department of physics, JNTUA, Anantapuramu (A.P), India
}

*Corresponding author: Suresh Kumar N, Department of physics, JNTUA, Anantapuramu, India

\begin{abstract}
The metals U(VI) and Pd (II) gives yellow coloration with the reagent 4-Hydroxy benzaldehyde thiosemicarbazone(4-HBTS) in acidic medium simultaneous determination of both the metal ions U(VI) and Pd (II) can be done by using second order derivative spectrophotometric technique. For the determination of composition of metal complexes Job's method and mole ratio method were employed.
\end{abstract}

Keywords: Derivative Spectrophotometry; Thiosemicarbazone; 4-HBTS

\section{Introduction}

Uranium is hexavalent and palladium is divalent transition metals. Uranium is a highly reactive metal, especially at elevated temperatures. Uranium is radioactive, and is the element for which the phenomenon of radioactivity was first discovered. Palladium is little harder than pure platinum and it is catalytically active in the colloidal state. Simultaneous determination of these two metal ions becomes difficult and poses many problems. A second order derivative spectrophotometric method is used for the simultaneous determination of two metal ions based on their reaction with 4-hydroxy benzaldehyde thiosemicarbazone (4HBTS). Thiosemicarbazones have wide range of analytical applications in the determination of metal ions [1-5]. Thiosemicarbazones can be synthesized easily (Figure 1). Thiosemicarbazones forms stable complexes with different metal ions [6-13]. For getting improved resolution of spectral bands derivative spectrophotometry is chosen, for resolving two overlapped spectra and to eradicating matrix interferences in two component mixtures zero crossing method can employed [14,15]. Two simultaneous equations should be solved for the determination of components in a mixture in the absence of zero crossing point $[16,17]$. Without solving simultaneous equations, derivative spectrophotometric technique can be employed for analysis of two component mixtures $[18,19]$. The tolerance limit value of foreign increases using derivative spectrophotometric technique which intern decreases the interference of foreign ions. Resolution of spectral bands can be achieved using derivative spectrophotometry, which allows location and detection of wavelength of complex spectra which is poorly resolved and also decrease the effect of interferences of spectral background. Simultaneous determination of metal ions by derivative spectrophotometric technique is not much exploited [20-22]. 
<smiles>[3H][Al]=[Te][Te]</smiles>

4-hydroxy

Thiosemicarbazide
4-HBTS

benzaldehyde

Figure 1: The yield remained $80 \%$ by weight and the melting point is $207^{\circ} \mathrm{C}-209^{\circ} \mathrm{C}$. The compound structure was originated using infrared and nuclear magnetic resonance spectra.

\section{Experimental Part}

Shimadzu UV-Visible spectrophotometer (model UV-160A) used for the measurement of absorbance values and $\mathrm{pH}$ measurements were made by Elico digital pH meter (modelLI20).

\section{Preparation of 4-hydroxy benzaldehyde thiosemicarbazone}

1 mole (1.22gm) of 4-hydroxy-benzaldehyde taken in $100 \mathrm{ml}$ of methanol and 1-mole $(0.92 \mathrm{gm})$ of thiosemicarbazone taken in hot water were mixed together in a clean $250 \mathrm{ml}$ round bottomed flask and refluxed for about 2 hours. Condensation reaction takes place and a brown colour product was observed, which is collected by filtration. With the help of methanol, the reagent was recrystallized and dried up in vacuum.

\section{Characterization}

Perkin-Elmer 137 infrared spectrometer is used for IR spectrum of the compound in $\mathrm{KBr}$. The assymmetric as well as symetric $(-\mathrm{N}-\mathrm{H})$ steching frequencis assigned to primary amino-group are noticed at $3458 \mathrm{~cm}^{-1}$ and $3342 \mathrm{~cm}^{-1}$. frequency of aromatic proton (Ar-H) is observed at $3218 \mathrm{~cm}^{-1}$. The peak noticed at $1595 \mathrm{~cm}^{-1}$ is ascribed to $\mathrm{C}=\mathrm{N}$ stretching frequency of azomethine. The peak for $-\mathrm{OH}$ group is obeserved at 3028-3092 $\mathrm{cm}^{-1}$. C=S stretching frequency is observed as strong peak at $1056 \mathrm{~cm}^{-1}$. The peaks for aromatic ring stretching frequency are observed in the range of $1530^{-1} 360 \mathrm{~cm}^{-1}$ frequency. DRX 300 NMR spectrophotometer was used to record H-NMR spectrum. The charectarisation of phenolic $\mathrm{OH}$ gives a peak noticed at $\delta$-value $10.74(1 \mathrm{H})$. the peak for aromatic proton was observed at a peak attained at $\delta$-value $7.86(4 \mathrm{H})$ the peak recorded at $\delta$-value $6.8(2 \mathrm{H})$ can be assigned to $-\mathrm{NH}_{2}$ proton assigned to thionyl $(\mathrm{C}=\mathrm{S})$ group. the aldehydic proton gives a peak detected at $\delta$-value 9.0. The -NH proton (Azomethine) given a peak at $\delta$ value 11.5 .

\section{Results and Discussion}

The precursors, $1 \mathrm{ml}$ of $1 \times 10^{-3} \mathrm{M}$ uranyl acetate and $1 \mathrm{ml}$ of 1 x $10^{-3} \mathrm{M}$ palladous chloride are taken in a $25 \mathrm{ml}$ volumetric flask. $10 \mathrm{ml}$ of buffer-solution of pH 5 is added. The reagent 4-hydroxy benzaldehyde thiosemicarbazone (4-HBTS) is taken in such a way that it is ten times in excess of both the metal ions. The mixture in the flask are made up the mark with distilled water. A blank solution is also prepared without adding the metal ion. The zero order spectra of U (VI) and 4-HBTS; Pd (II) and 4-HBTS are recorded in a buffer solution ( $\mathrm{pH} 5$ ). They are shown in (Figures 2,3) respectively. The $\lambda_{\text {max }}$ values of the metal ions are $348.5 \mathrm{~nm}$ and $359 \mathrm{~nm}$ respectively. The zero-order spectrum of the solution containing both the metal ions is also recorded under the same experimental condition and presented in (Figure 4). It can be observed from this figure that the solution containing the mixture of metal ions shows only one peak at $355 \mathrm{~nm}$. Hence it is not possible to determine U(VI) and Pd (II) simultaneously employing zero order spectrum. Attempts are made by the author to use the first order derivative spectrophotometric technique for the simultaneous determination, but the outcomes are not favorable. The author therefore adopted second order derivative spectrophotometric technique for the simultaneous determination of U(VI) and Pd (II). 


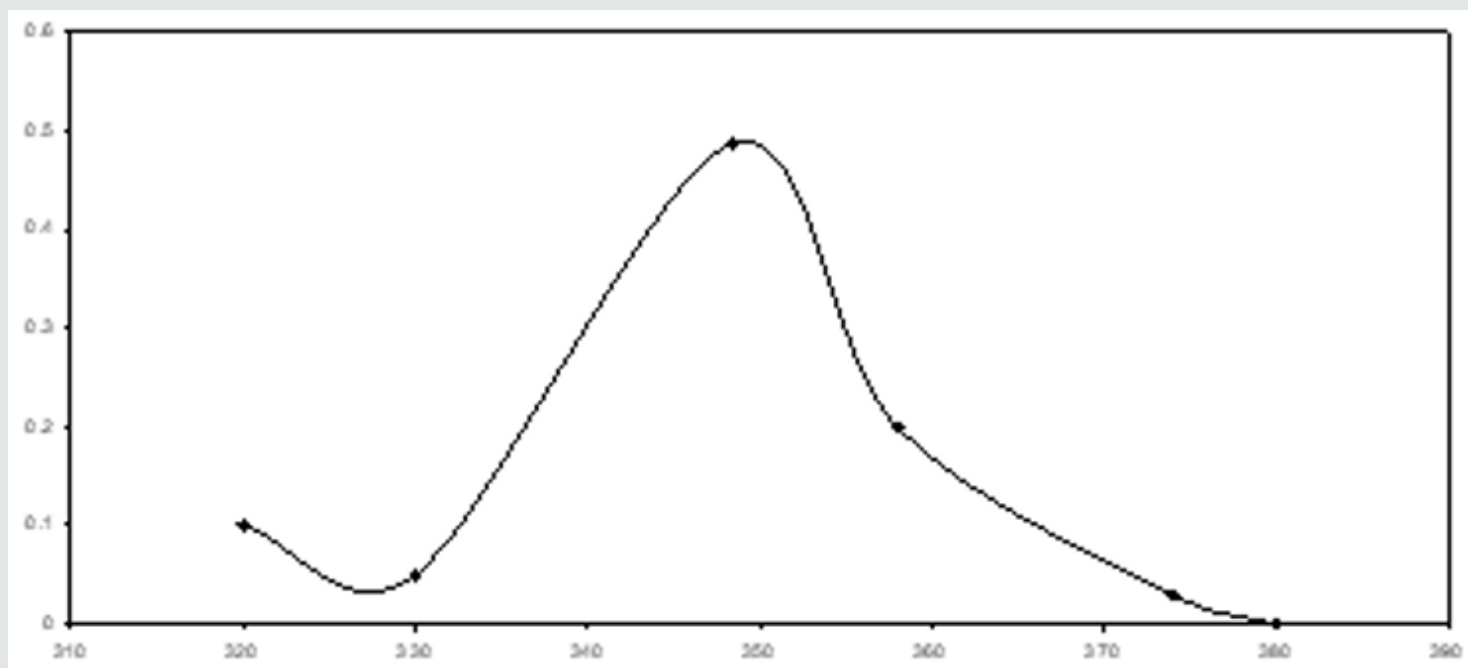

Figure 2: Zero order spectrum of uranium in presence of $4-\mathrm{HBTS},[\mathrm{U}]=1 \times 10^{-3} \mathrm{M},[4-\mathrm{HBTS}]=1 \times 10^{-2} \mathrm{M}, \mathrm{pH}=5$.

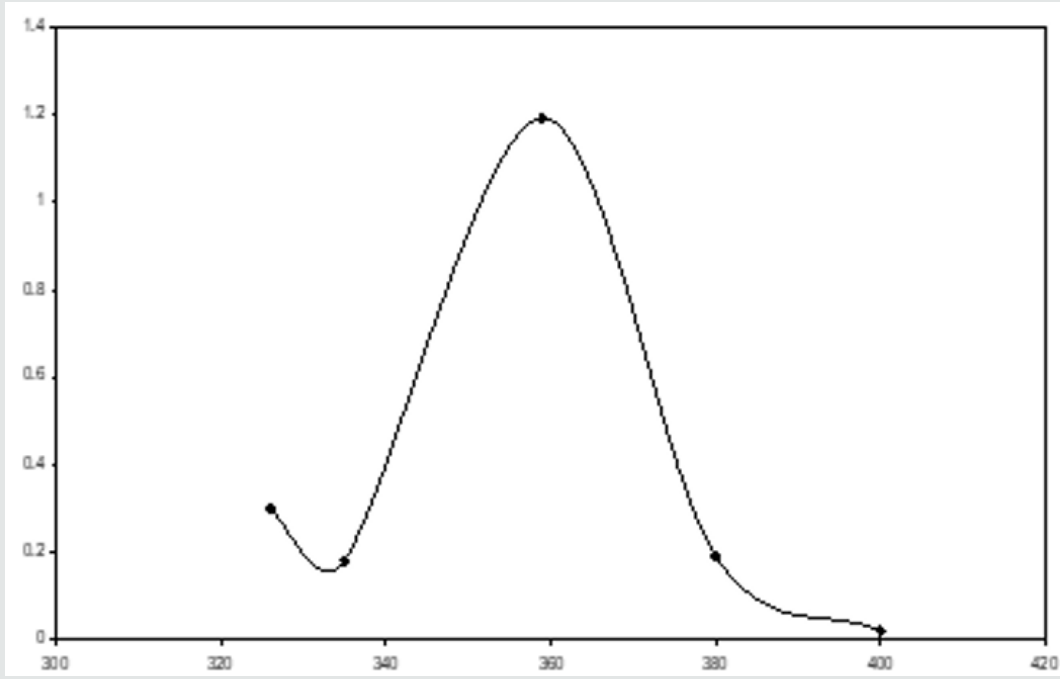

Figure 3: Zero order spectrum of palladium in presence of $4-\mathrm{HBTS},[\mathrm{Pd}]=1 \times 10^{-3} \mathrm{M},[4-\mathrm{HBTS}]=1 \times 10^{-2} \mathrm{M}, \mathrm{pH}=5$.

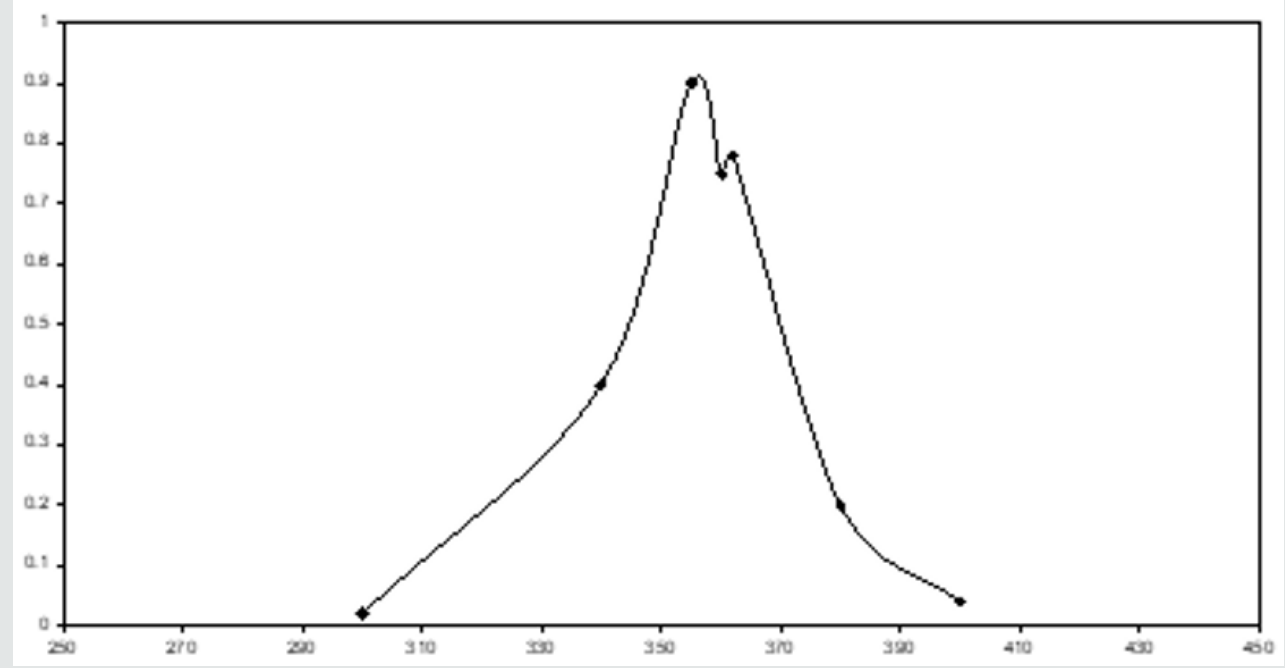

Figure 4: Zero order spectrum of $(\mathrm{U}+\mathrm{Pd})$ in presence of $4-\mathrm{HBTS},[\mathrm{Pd}]=1 \times 10^{-3} \mathrm{M},[\mathrm{U}]=1 \times 10^{-3} \mathrm{M},[4-\mathrm{HBTS}]=1 \times 10^{-2} \mathrm{M}$, $\mathrm{pH}=5$. 


\section{Simultaneous determination of U(VI) and Pd (II)}

A series of solutions are prepared containing varying concentrations of U(VI) and Pd (II). An excess of the reagent is added to each of these solutions. The solution is made up to the mark by adding required volume of buffer ( $\mathrm{pH} \mathrm{5)}$ and distilled water. An absolute solution is made on the same limes but deprived of metal ions. The second order derivative spectrum is recorded for the experimental solution. Typical spectrum is presented in (Figure 5). From the figure, it is clear two peaks are observed for corresponding two metal ions $410 \mathrm{~nm}$ and $440 \mathrm{~nm}$ and two valleys at $429 \mathrm{~nm}$ and $454 \mathrm{~nm}$. Under the same conditions, the second order derivative spectra are recorded individually for both metal ions. The outcomes disclosed that the peak and valley at $410 \mathrm{~nm}$ and $425 \mathrm{~nm}$ correspond to Pd (II) and the peak and valley at 440 $\mathrm{nm}$ and $454 \mathrm{~nm}$ corresponding to U(VI).

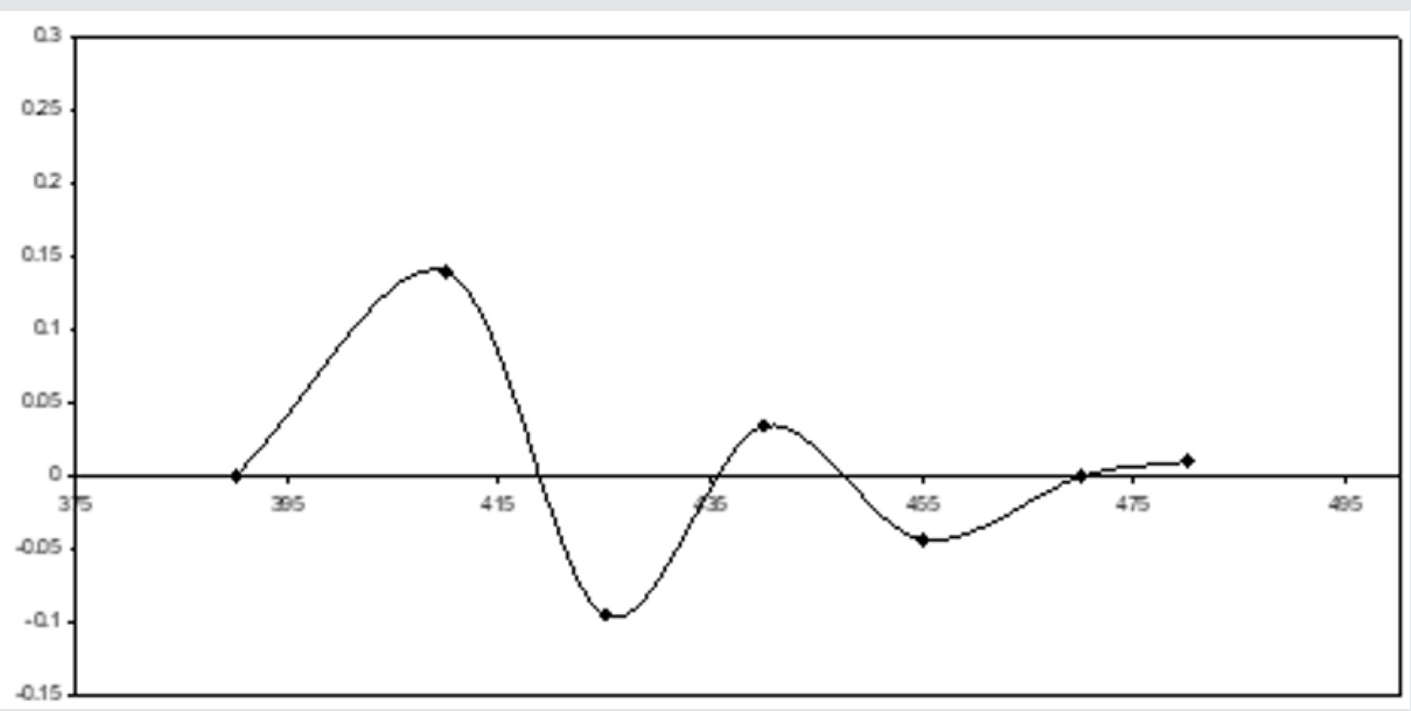

Figure 5: Typical second order spectrum of $\mathrm{U}+\mathrm{Pd}$ in presence of $4-\mathrm{HBTS},[\mathrm{U}]=3 \times 10^{-4} \mathrm{M},[\mathrm{Pd}]=3 \times 10^{-4} \mathrm{M},[4-\mathrm{HBTS}]=2 \times 10^{-2} \mathrm{M}$, $\mathrm{pH}=5$.

In addition, the measurements are made on the respective amplitudes of peak and valley are shown in the (Figure 6) for both metal ions. Graphs are drawn between the respective metal ion concentration and peak amplitude for uranium as well as palladium. Besides, maintaing the same conditions second-order derivative spectra are recorded for individual metal ions. The suitability of this method is established by the linear plots obtained for the simultaneous determination of U(VI) \& Pd(II) in the acidic medium. The straight line plots are obtained when the graphs are ploted by taking the sum of peaks \& vallies amplitues for individual metal ions. Fig. 6 indicates the straight lines obtained and uranium is estimated in the range 4.7604 to $38.083 \mu \mathrm{g} / \mathrm{ml}$ and palladium is estimated from 2.128 to $17.024 \mu \mathrm{g} / \mathrm{ml}$ by using this method (Figure 7).

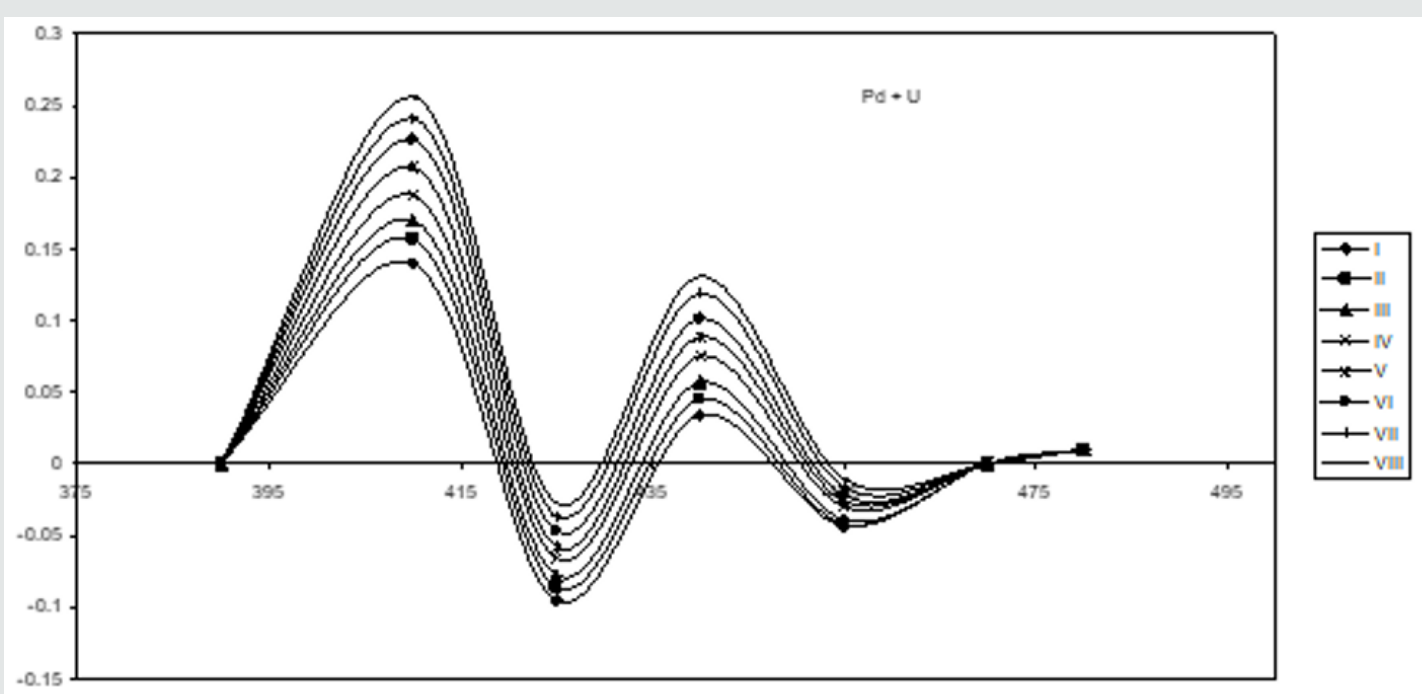

Figure 6: Second order spectra of $\mathrm{U}+\mathrm{Pd}$ in presence of $4-\mathrm{HBTS},[\mathrm{U}]=3 \times 10^{-4} \mathrm{M},[\mathrm{Pd}]=3 \times 10^{-4} \mathrm{M},[4-\mathrm{HBTS}]=2 \times 10^{-2} \mathrm{M}$. $\mathrm{pH}=5$. 


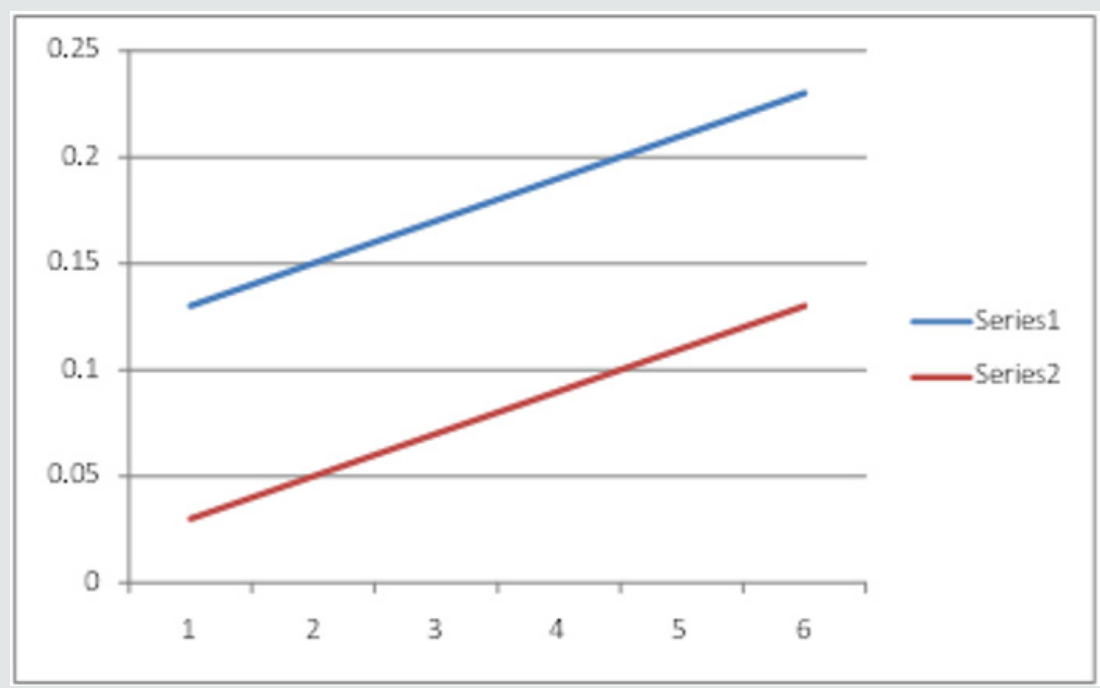

Figure 7: Verification of Beer's law for Series 1- U (VI) and Series 2- Pd (II).

\section{Tolerance effect}

Tolerance limit of different metal ions associated with U(VI) and Pd(II) is investigated. Influence of several anions is also studied.
The appropriate data is presented in Table 1. An analysis of the data reveals that $\mathrm{Cu}$ (II), Ni (II), V(V) and $\mathrm{Cr}$ (VI) did interfere seriously in the determination of metal ions. Utmost of the anions does not interfere.

Table 1: Tolerance limit of foreign ion in the determination of $0.952 \mu \mathrm{g} / \mathrm{ml}$ of U(VI) \& $0.424 \mu \mathrm{g} / \mathrm{ml}$ of Pd (II).

\begin{tabular}{|c|c|c|c|c|c|}
\hline \multirow{2}{*}{ Ion added } & \multicolumn{2}{|c|}{ Tolerance-limit $(\mu \mathrm{g} / \mathrm{ml})$} & \multirow{2}{*}{ Ion added } & \multicolumn{2}{|c|}{ Tolerance limit $(\mu \mathrm{g} / \mathrm{ml})$} \\
\hline & U (VI) & Pd (II) & & $\mathrm{U}(\mathrm{VI})$ & Pd (II) \\
\hline Chloride & 170 & 142 & Cadmium (II) & 11.24 & 4.5 \\
\hline Bromide & 319 & 255 & Manganese (II) & 17.58 & 2.2 \\
\hline Acetate & 424 & 236 & Nickel (II) & 5.86 & 2.35 \\
\hline Nitrate & 496 & 248 & Copper (II) & 2.54 & 2.54 \\
\hline Tartarate & 736 & 736 & Vanadium (V) & 1.63 & 12.22 \\
\hline Sulphate & 313 & 313 & Chromium (VI) & 1.039 & 1.039 \\
\hline
\end{tabular}

\section{Application}

The method developed by the author has been employed for the simultaneous determination of U(VI) \& Pd (II) in simulated mixtures. The outcomes are presented in Table 2 and they are satisfactory.

Table 2: Analysis of simulated mixture (U (VI) and Pd (II)), *Average of five determinations.

\begin{tabular}{|c|c|c|}
\hline Amounts taken* $(\boldsymbol{\mu g} / \mathrm{ml})$ & Found $(\boldsymbol{\mu g} / \mathbf{m l})$ & \% of error \\
\hline 0.525 & 0.515 & 1.9 \\
\hline 0.843 & 0.833 & 1.18 \\
\hline
\end{tabular}

\section{Conclusion}

The current work is simple, sensitive and highly selective for the simultaneous determination of U(IV) \& Pd (II) in admixtures by second order derivative spectrophotometric technique without separation as well as solving the simultaneous equations. The technique developed has been applied for the simultaneous determination of U(IV) and Pd (II) in simulated mixtures.

\section{References}

1. Smita Nigam, Patel and Arabinda Ray, Synth (1998) Spectrophotometric determination of $\mathrm{Cu}$ (II) and $\mathrm{Ni}$ (II) using 4-hydroxybenzaldehyde thiosemicarbazone Reat. Inorg. Met-Org. Chem, 3(4): 2062-2065.

2. Hussain Reddy K, Sambasiva Reddy P, Ravindra Babu P (1999) Synthesis, Structural Characterization and DNA Studies of Nickel (II) Complexes of (2E)-4N-Substituted-2-[4-(propan-2-yl) Benzylidene] Hydrazinecarbothioamide Schiff's Bases J Inorg Biochem 8(10): 61-68.

3. Noriko CK, Kiyoshi S, Chisa K, Nobuhiro Sa, Motokoi I, et al. (2001) A Study on spectrophotometric determination of copper from wastewater and its removal using magnatite nanoparticles. J Inorg Biochem 84: 5565.

4. Javier GT, Jose LP, Africa G, Ana Rocio P, Maria U, et al. (2001) Synthesis, structure and biological activity of cobalt (II) and copper (II) complexes of valine-derived schiff bases. J Inorg Biochem 86(6): 27-633.

5. EI Mostapha J, Amedeerio, Magali A, Mustayeen AK, Gilles MB (2001) Environmental risks of anthropogenic metals and their spectrophotometric determination using 4-hydroxy benzaldehyde thio semicarbazone Polyhedron 20: 67-69.

6. Malik AK, Kaul KN, Lark BS, Faube W, Rao AL, et al. (2001) Sorption Study of Nickel (II) in Glycine Medium Using Poly [dibenzo-18 crown-6] and Column Chromatography. J Turk J Chem 25: 99. 
7. Ferreira SLC, Santos BF, de Andrade JB, Spinola C, et al. (2008) A Glimpse of Recent Developments in Brazilian Analytical Chemistry Michro chim Acta 122: 109.

8. Kumar A, Jain M (1992) Effects of adsorption of electroactive species in stationary electrode polarography. Chem Anal 39: 73.

9. Bansal AK, Nagar MJ (2006) A Critical Review on Analytical and Biological Applications of Thio- and Phenyl thiosemicarbazones. Indian chem Soci 83: 731.

10. Odashima T, Kohata K, Yogi K, Ishii H, Bunseki K (1995) Selective Determination of Nickel (II) in Water, Effluent and Alloy Samples Using Isonicotinohydroxamic Acid as Analytical Reagent 44 (2): 135.

11. Boladani SN, Tewari M, Agarawal A, Sekhar KC (1994) Environmental risks of anthropogenic metals and their spectrophotometric determination using 4-hydroxybenzaldehydethiosemicarbazone Fr J Anal chem 349(6): 478.

12. Satheesh KP, Suryanarayana RV (2014) J Indian chemical soc 91: pp. 853-858.

13. Satheesh KP, Suryanarayana Rao V (2014) Environmental risks of anthropogenic metals and their spectrophotometric determination using 4-hydroxybenzaldehydethiosemicarbazone Archives of applied Science research 6(3): 23-28.

14. Wahbi AM, Abdine H, S Balaiah (1977) J Assoc Off Anal Chem 60: 1175.

15. Bedair M, Korany MA, Yazbi EI (1986) Simultaneous Second Order Derivative Spectrophotometric Determination of Gallium (III) and Aluminium(III) using Diacetylmonoxime IsonicotinoylHydrazone. Sci F A Pharma 54: 31
16. MA Korany, AM Wahbi, MA Elasayed, S Mandour (1984) Determination of ethinyloestradiol in the presence of norethisterone by derivativedifference spectrophotometry. Springer 7(4): 163-166.

17. Hussain KR, Chandrasekhar KB (2001) derivative spectrophotometric determination of nickel (ii) using 3,5-dimethoxy-4-hydroxy Benzaldehyde isonicotinoyl hydrazone(dmhbih). Rasayan J chem 3(3): 467-472.

18. Chandrasekhark KB, Reddy KH, Sreenivasula TR (2003) J Indian Chem Soc 80: 930 .

19. Chandrasekhar KB, Reddy KH, Devana N (2002) Derivative Spectrophotometric Determination of Ruthenium (III) using Cinnamaldehyde Isonicotinoylhydrazone (CINH). Indian J Chem 41(A): 1643.

20. Chandrasekhar KB, Reddy KH, Devana N (2002) Derivative Spectrophotometric Determination of Ruthenium (III) using Cinnamaldehyde Isonicotinoylhydrazone (CINH). Indian J Chem 41(A): 1643.

21. Rameswara MR, Chandrasekhar KB, Devanna N (2011) Archives of Applied Science Research 3 (1): 462.

22. Gopala Krishna D, Devanna N, Chandrasekhar KB (2010) Comparative study of Palladium (II) using 4-Hydroxy 3, 5 dimethoxy benzaldehyde 4-hydroxy benzoyl hydrazone and Cinnamaldehyde 4-hydroxy benzoylhydrazone in presence of micellar medium by Spectrophotometry International Journal of Pharma Sciences and Research 1(8): 301-311.
To Submit Your Article Click Here:

This work is licensed under Creative Commons Attribution 4.0 License

Submit Article

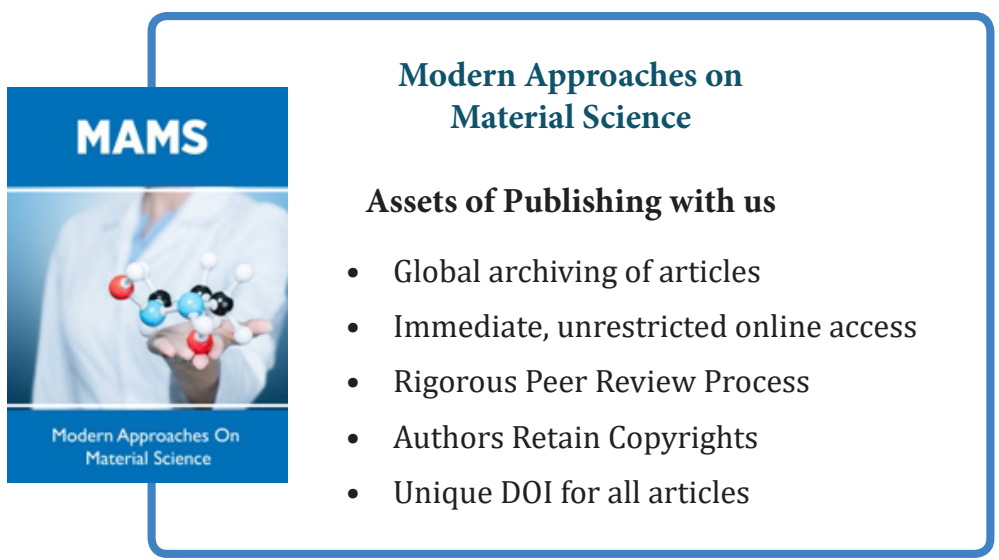

